\title{
DESIGN AND ANALYSIS OF STRESS RIBBON BRIDGES
}

\author{
Siddhartha Ray ${ }^{1}$, D. M. Joshi ${ }^{2}$, Rahul Chandrashekar ${ }^{3}$ \\ ${ }^{I}$ M. E. student, Department of Civil Engineering, S. C. O.E., Kharghar, Maharashtra, India \\ ${ }^{2}$ Assistant Professor., Department of Civil Engineering, S. C. O.E., Kharghar, Maharashtra, India \\ ${ }^{3}$ Design Engineering, Precast, L \& T Construction, Maharashtra, India
}

\begin{abstract}
A stressed ribbon bridge (also known as stress-ribbon bridge or catenary bridge) is primarily a structure under tension. The tension cables form the part of the deck which follows an inverted catenary between supports. The ribbon is stressed such that it is in compression, thereby increasing the rigidity of the structure where as a suspension spans tend to sway and bounce. Such bridges are typically made RCC structures with tension cables to support them. Such bridges are generally not designed for vehicular traffic but where it is essential, additional rigidity is essential to avoid the failure of the structure in bending. A stress ribbon bridge of 45 meter span is modelled and analyzed using ANSYS version 12. For simplicity in importing civil materials and civil cross sections, CivilFEM version 12 add-on of ANSYS was used. A $3 D$ model of the whole structure was developed and analyzed and according to the analysis results, the design was performed manually.
\end{abstract}

Keywords: Stress Ribbon, Precast Segments, Prestressing, Dynamic Analysis, Pedestrian Excitation.

$* * *$

\section{INTRODUCTION}

Stress-ribbon bridge is the term that has been created to describe on which pedestrians can directly walk and is in the shape of an inverted arch. The structure consists of tensioned cables which have slight sag in them, embedded in a concrete deck which is very slender when compared with the span. This deck serves the purpose of distributing the loads and to maintain the continuous nature of the deck,. It is a type of a suspended structure where the cables are tensioned so tightly that the pedestrian load can be placed directly on the concrete deck in which the cables are embedded. It's a very simple structure when compared to other complex structures like suspension bridges. The only drawback of these bridges is the very fact that the tensioning force is so high in the cables that one has to anchor its abutments which makes the bridge expensive.

A stressed ribbon bridge is a structure primarily in tension which is very similar structurally to suspension bridges. The design of such bridges is very rare in the world. Very few engineers as such understand its form and behaviour and hence such bridges are not common in the world. Unlike a simple suspension bridge, the ribbon is stressed in compression which increases the stiffness of the structure. Such bridges are typically made RCC structures with tension cables to support them. They are primarily used for pedestrians but bicycles may be allowed based on design. Such bridges, generally are maintenance free, architecturally appeasing and economical when compared with their spans. The slender deck allows them to make the minimum use of construction material. In the current scenario, research is being carried out to find the most viable variation of the structure by combining it with arches.

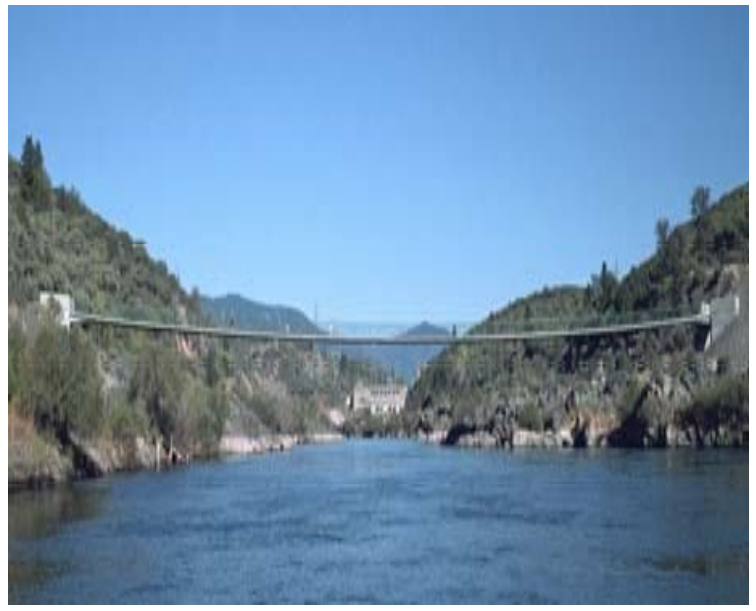

Fig. 1 Redding Pedestrian stress ribbon bridge.

There are 3 types of stress ribbon bridges, namely traditional, stress ribbon bridges supported on an arch and stress ribbon bridge suspended on an arch. Fig. 1 is an example of a traditional stress ribbon bridge.

For stress ribbon bridges supported on arches, the arch acts as a temporary support wherein the deck can rise during and fall during various loading states and temperature fluctuations. The Fig. 2a shows the general structural arrangement of a stress ribbon bridge supported on arches. In its initial stages, it resembles its behaviour as a two-span cable, supported by the central support that is anchored to the end abutments (ref. Fig.2b). The supporting arch is stressed by its own weight in addition to that of the deck, the self-weight of the support members and the radial forces exerted by the tensioned cables (ref. Fig.2c) [4]. After posttensioning the entire structure behaves as one.

The thrust forces in the stress ribbon $\mathrm{H}_{\mathrm{SR}}$ and the arch $\mathrm{H}_{\mathrm{A}}$ play a critical role since they have to be chosen in such a 
manner that they are equal. If the aforementioned criteria are met, the stress ribbon and the arch can be connected by and inclined strut which shall primarily be in compression. An overturning moment shall be created by cable thrust $\mathrm{H}_{\mathrm{SR}}{ }^{*} \mathrm{~h}$ which shall be balanced by the arch reaction $\Delta \mathrm{V}^{*} \mathrm{~L}_{\mathrm{P}}$. Hence a self-balancing mechanism is created (ref Fig.2d) [4]. Another alternative is to suspend the stress-ribbon from the arch. Self-balancing systems can be made for the same as well.

Fig. 3a, shows a fixed arch at the end anchorages of a slender prestressed concrete deck. The loadings on the arch is its ownself weight in addition to the self-weight of the stress-ribbon combined with the radial forces of the tensioning cables. Fig. 3bpresents a statically similar structure as represented in Fig. 2d. Fig. 3 c presents a condition wherein the thin prestressed deck with additional flexural rigidity in the unsupported section of the structure [[4]].

a)

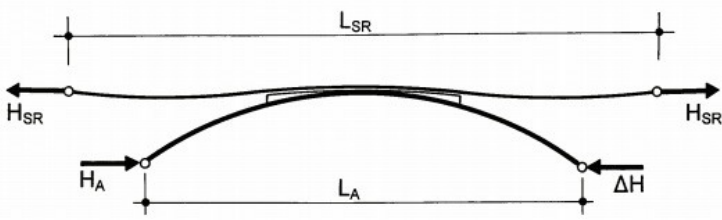

b)

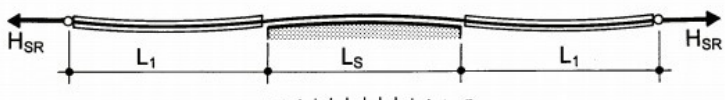

c)

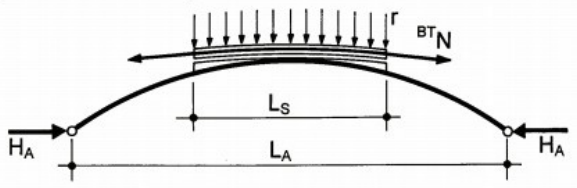

d)

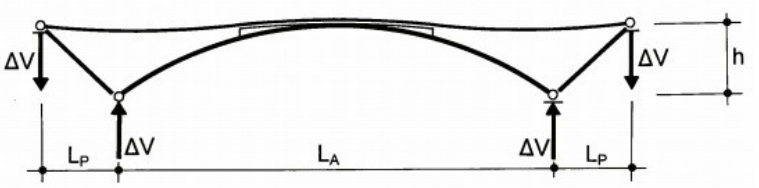

Fig. 2 Stress ribbon supported by arch.

a)
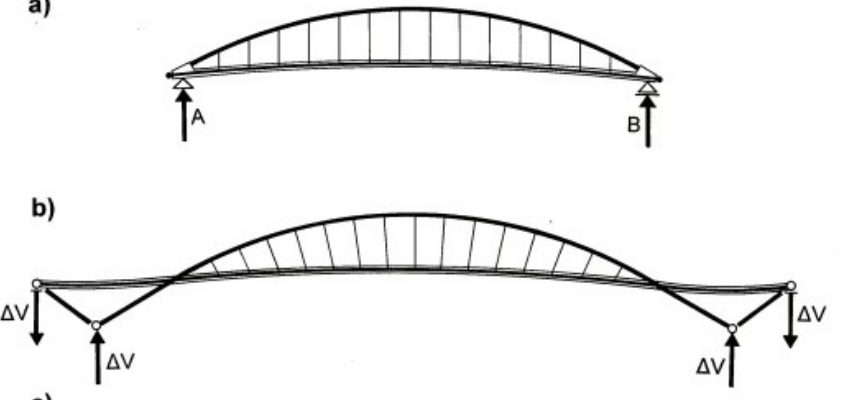

c)

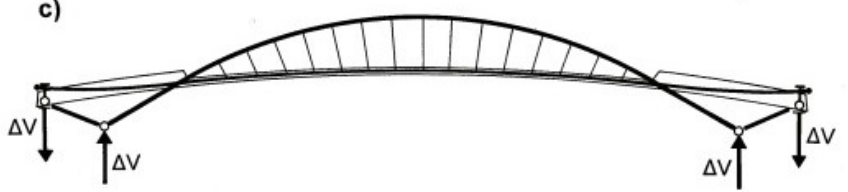

Fig. 3 Stress ribbon suspended on arch.

The aim of the present study is to analyse a traditional stress ribbon for a span of 45 meters for IRC loading conditions and a safety check for pedestrian excitation.

\section{MODELING AND ANALYSIS RESULTS}

The deck segment selected was 4 meters wide, $250 \mathrm{~mm}$ thick and 1 meter long. The bridge would consist of 45 such segments supported on bearing cables. The meshing was performed according to the length of segments. The deck had to be given a sag by the formula $f=0.02 * L$ where $\mathrm{L}$ is the length of the bridge [3]. The final geometric model of the bridge is shown in Fig. 4.

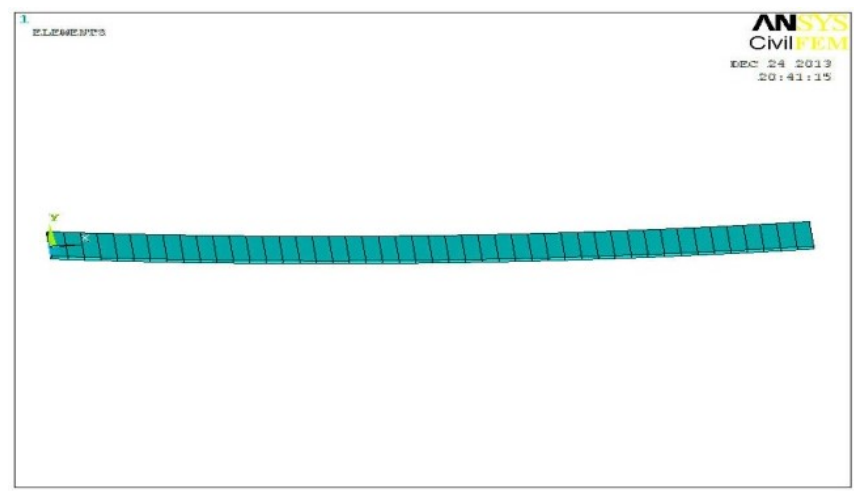

Fig. 4 Final geometric model.

The structure was loaded with live, wind and temperature loads as per IRC 6-2010. Wind and temperature loads were calculated for Mumbai region. The force in the bearing cable was calculated as per $P=\frac{w * L^{2}}{8 * f}$, where $\mathrm{w}$ is the self weight intensity of the bridge deck [3]. The cable forces come to $7320 \mathrm{kN}$ which will require $412 \mathrm{~K} 15$ prestressing cables to transfer the load to the abutment. The structure was analyzed in ANSYS for the individual load cases and load combinations as per IRC 6-2010. The results are shown in table 1 .

Table 1. Loading Results

\begin{tabular}{|l|l|l|l|l|}
\hline $\begin{array}{l}\text { Sr. } \\
\text { No. }\end{array}$ & Load Case & \multicolumn{2}{|l|}{$\begin{array}{l}\text { Bending } \\
\text { Moment } \\
(\mathbf{k N m}) \\
\text { Maximum }\end{array}$} & $\begin{array}{l}\text { Deflection } \\
(\mathbf{m m})\end{array}$ \\
\hline 1 & Live Load & Sag & Hog & \\
\hline 2 & $\begin{array}{l}\text { Transverse Wind } \\
\text { Load }\end{array}$ & - & - & 0.3 \\
\hline 3 & Vertical Wind Load & 36 & 72 & 22.36 \\
\hline 4 & Temperature Load (+) & 80 & 158 & 49.26 \\
\hline 5 & Temperature Load (-) & 158 & 80 & $\begin{array}{l}49.26 \\
\text { (upward) }\end{array}$ \\
\hline 6 & Normal Combination & 104 & 212 & 65.66 \\
\hline 7 & $\begin{array}{l}\text { Temperature } \\
\text { Combination }\end{array}$ & 184 & 370 & 115 \\
\hline 8 & $\begin{array}{l}\text { Wind \& Temperature } \\
\text { Combination }\end{array}$ & 219 & 443 & 137.3 \\
\hline
\end{tabular}


The critical load combination in terms of prestressing steel comes out to the temperature combination which also proves that stress ribbons are critical to temperature [3]. It was for this combination the design was carried out as per IRC 182000 manually and 6, 4K 15 cables stressed at a force of 800 $\mathrm{kN}$ each, including losses was found out as the post tensioned steel requirement.

The structure was then analyzed for the different critical prestressing conditions in ANSYS and the deflection for the structure in the final state under temperature combination and prestress is shown in Fig. 5. Also since stress is an important parameter under prestressing conditions the maximum stress results under temperature combination and prestress are also shown in Fig. 6. The table 2 shows the results due to prestress under transfer and temperature combination. Non critical cases and bending moments are not mentioned in table 2. Minimum reinforcement in the form of untensioned steel has to be provided in the segments for safety against temperature.

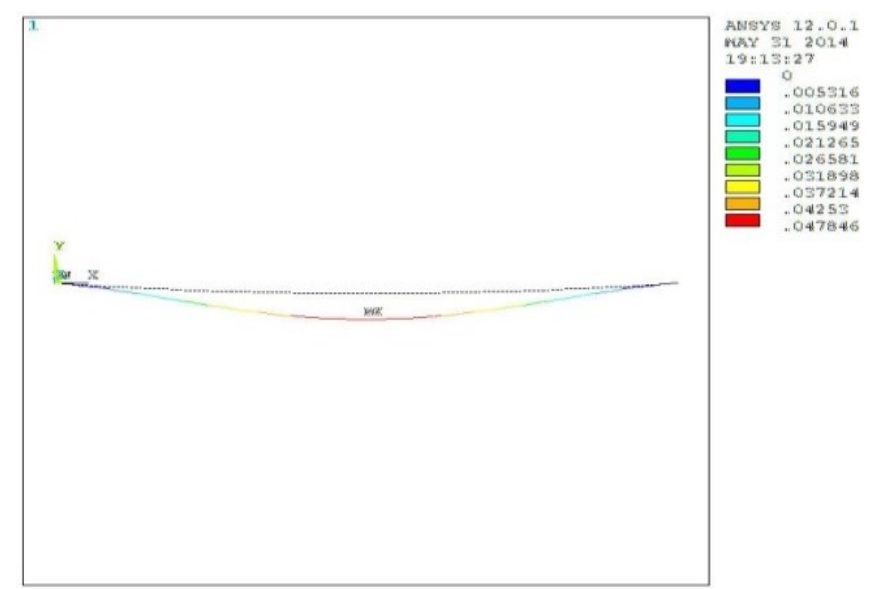

Fig. 5 Deflection due to temperature combination and prestress in meters.

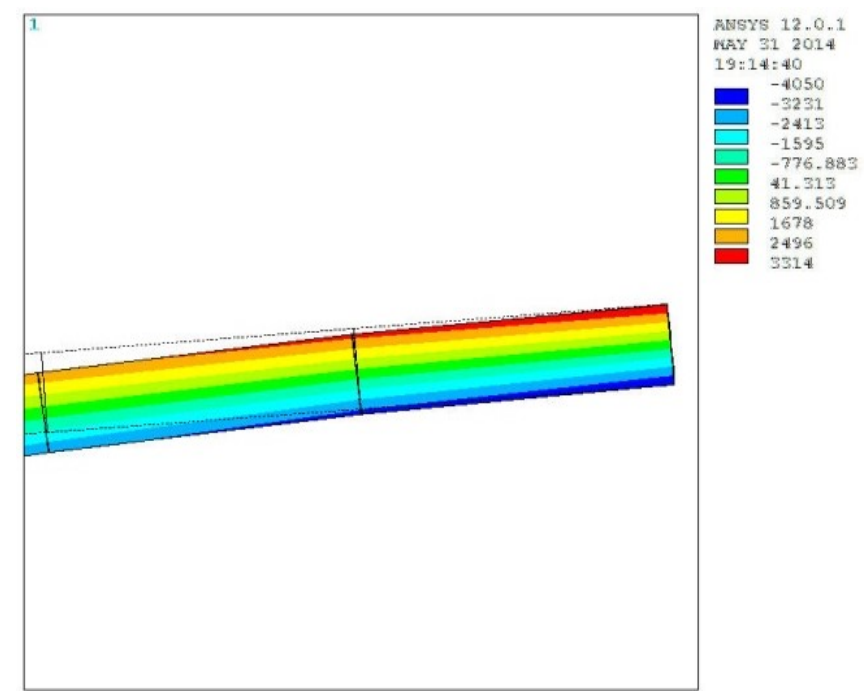

Fig. 6 Stress due to temperature combination and prestress in $\mathrm{kN} / \mathrm{m}^{2}$.
Table 2. Prestressing Results

\begin{tabular}{|l|l|l|l|l|l|}
\hline $\begin{array}{l}\text { Sr. } \\
\text { No. }\end{array}$ & $\begin{array}{l}\text { Load } \\
\text { Case }\end{array}$ & $\begin{array}{l}\text { Bending } \\
\text { Moment } \\
\text { (kNm) } \\
\text { Maximum }\end{array}$ & $\begin{array}{l}\text { Deflection } \\
(\mathbf{m m})\end{array}$ & $\begin{array}{l}\text { Stress } \\
\left(\mathbf{N} / \mathbf{m m}^{2}\right)\end{array}$ \\
\hline 1 & $\begin{array}{l}\text { Sead } \\
\text { Load \& } \\
\text { Prestress }\end{array}$ & Hog & 106 & $\begin{array}{l}67.08 \\
\text { (upward) }\end{array}$ & $\begin{array}{l}10.16 \\
(\text { Comp) } \\
\& 0.233 \\
(\text { Tensile })\end{array}$ \\
\hline 2 & $\begin{array}{l}\text { Prestress } \\
\& \\
\text { Temperat } \\
\text { ure } \\
\text { Combinati } \\
\text { on }\end{array}$ & - & - & 47.84 & $\begin{array}{l}4.06 \\
(\text { Comp) } \\
\& 3.31 \\
(\text { Tensile })\end{array}$ \\
\hline
\end{tabular}

The initial approach was to design a standard abutment that is generally used for bridges with the proportioning of its dimensions as given in standard books used for bridge engineering. The drawback however was that the horizontal deflection of the abutment due to the cable forces was very high, almost $400 \mathrm{~mm}$ deflection for 5 meter height of the abutment. Hence a stepped abutment was taken into consideration whose deflections were much lesser than the standard abutment. The cross sectional dimensions of the stepped abutment are shown below in Fig. 7. The top width of the abutment is $4 \mathrm{~m}$ which is the width of the deck of the bridge. A gradually decreasing drop of around $300 \mathrm{~mm}$ is provided so as to accommodate the first segment of the deck having a depth of $250 \mathrm{~mm}$ and an extra $50 \mathrm{~mm}$ for the provisions of elastomeric bearings while maintaining the slope of the deck. The bottom width of the abutment provided is $9 \mathrm{~m}$ so as to satisfy the S.B.C. conditions of the strata below. The stratum below is assumed as rock having a S.B.C. value of $900 \mathrm{kN} / \mathrm{m}^{2}$.

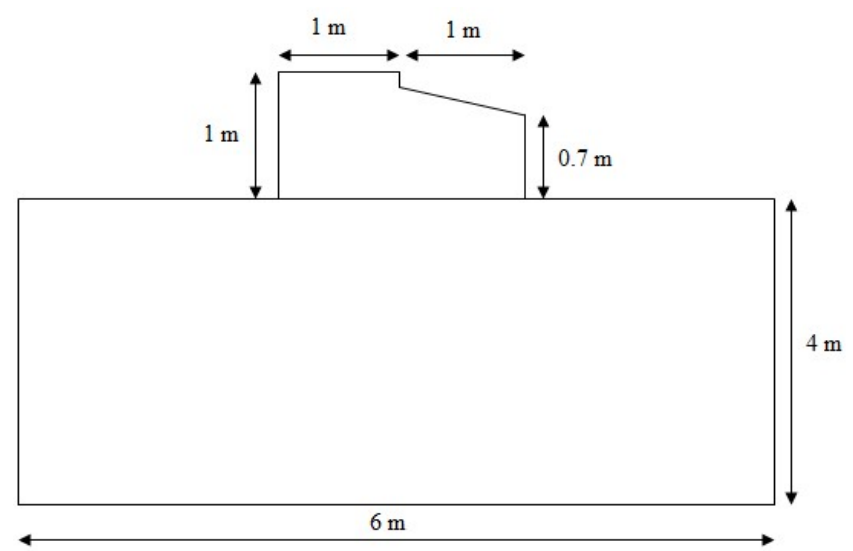

Fig. 7 Abutment cross section.

The most critical loading condition for the abutment is the cable forces acting on it [3] and structural engineers around the world design the abutment for cable forces only. The 
abutment was analyzed for cable forces in ANSYS and the bending moment results for the same are shown in Fig. 8. The design was performed manually as per IRC 21-2000 and the untensioned reinforcement for the top part of the abutment comes out to 20 tor bars @ $125 \mathrm{~mm}$ c/c and for the bottom part comes out to 32 tor bars @ $100 \mathrm{~mm} \mathrm{c/c}$.

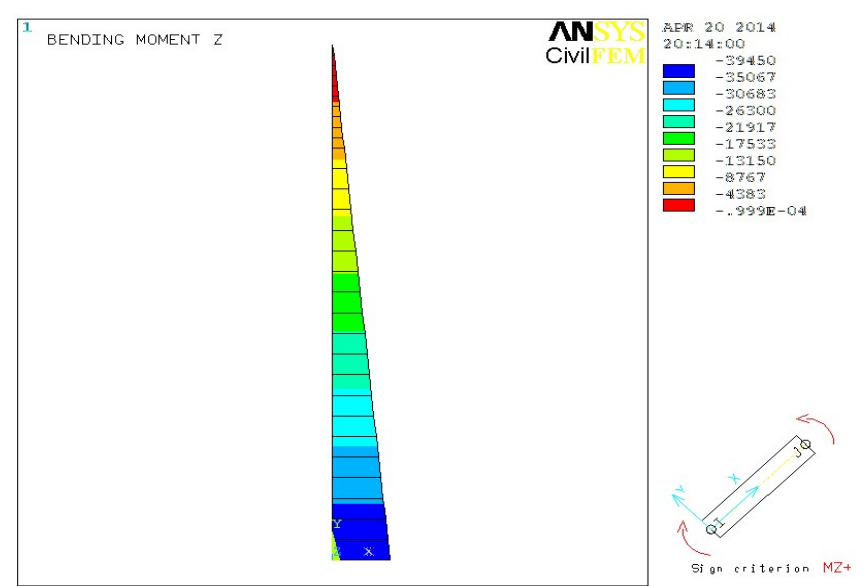

Fig. 8 Bending moment in abutment due to cable force in $\mathrm{kNm}$.

While most bridge abutments have only compressive forces on the soil, a stress ribbon bridge abutment will also have tension on its abutment base. The soil pressure results are shown in Fig. 9 under normal working conditions without any soil improvement methods. It is due these high tension forces on the abutment, rock anchoring is generally suggested to keep the abutment in place.

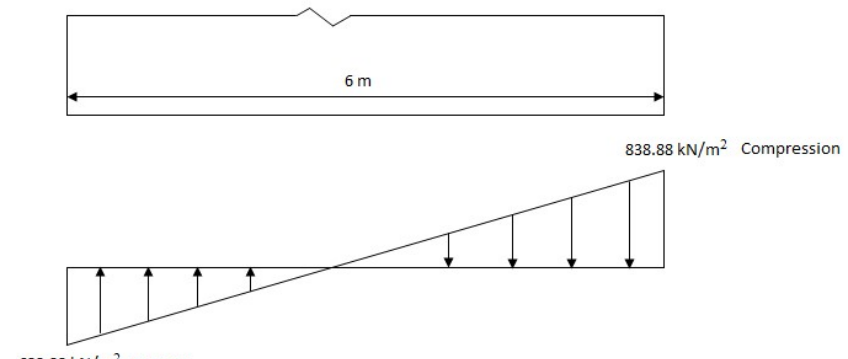

Fig. 9 Soil pressure results.

\section{DYNAMIC ANALYSIS AND PEDESTRIAN EXCITATION}

There are three primary mode shapes for the deck, namely, vertical, lateral and torsion modes. The first three modes are vertical. The first lateral mode is the fourth mode and the first torsional mode is the seventh mode.

The first two vertical modes have a frequencies $f_{l}=1.379 \mathrm{~Hz}$ and $f_{2}=1.788 \mathrm{~Hz}$ respectively and the mode shapes are shown in Fig. 10 and Fig. 11 respectively. Normal practice suggests that that the second mode $f_{2}$ shape should actually be the first mode shape but, this mode requires an elongation of the cable, hence the corresponding frequency in some cases is higher and mode shape of $f_{l}$ becomes the first mode $[3]$.
The first lateral mode is the fourth mode of the structure with a frequency $f_{4}=3.959 \mathrm{~Hz}$. Due to the vertical curvature of the prestressed band, a horizontal movement is always combined with torsion and it is therefore difficult to find a pure torsional mode [3]. The first torsional mode is the seventh mode for the structure with a frequency of $f_{4}=7.129 \mathrm{~Hz}$. Both the mode shapes are shown in Fig. 12 and Fig. 13 respectively.

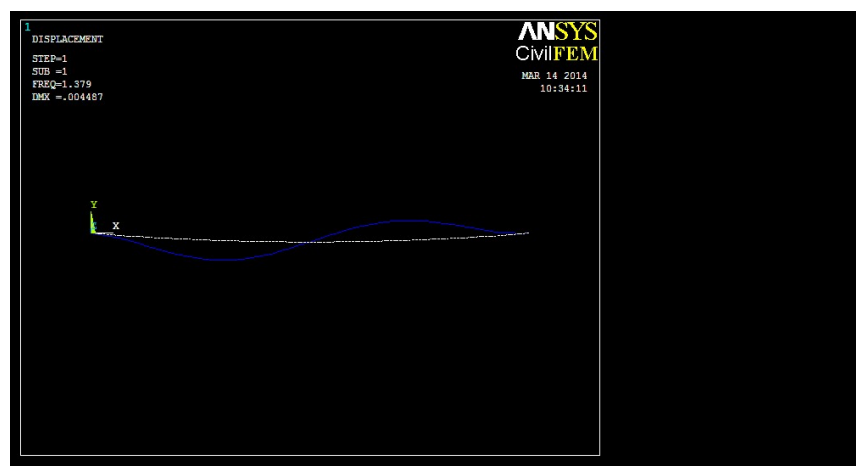

Fig. 10Mode shape for frequency $f_{l}=1.379 \mathrm{~Hz}$.

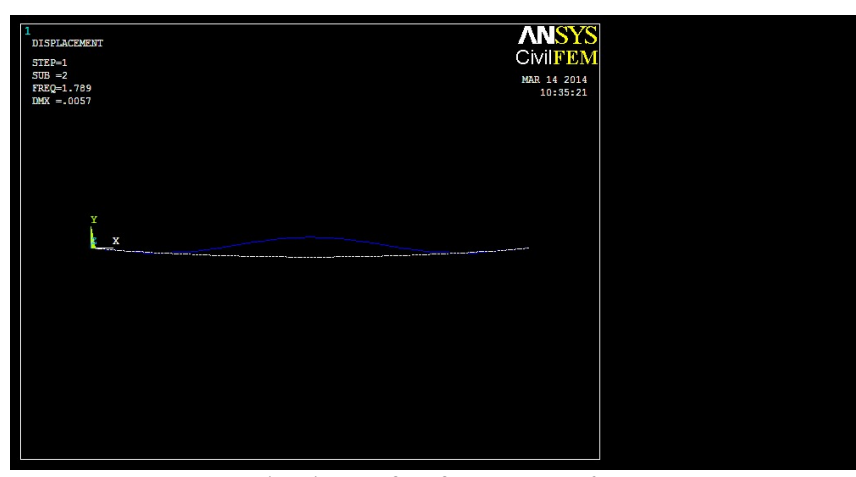

Fig. 11 Mode shape for frequency $f_{2}=1.788 \mathrm{~Hz}$.

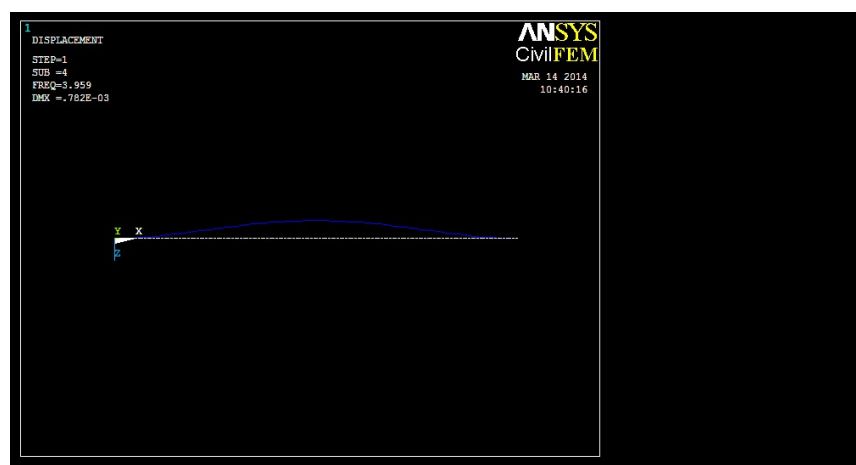

Fig. 12 Mode shape for frequency $f_{4}=3.959 \mathrm{~Hz}$.

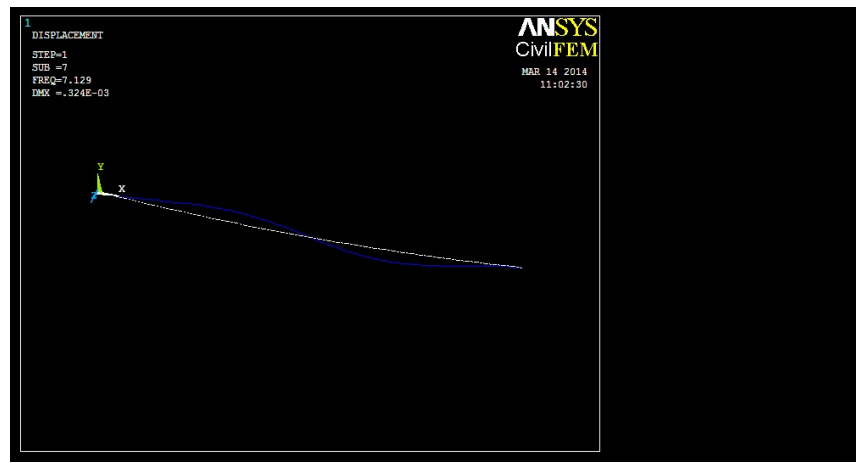

Fig. 13 Mode shape for frequency $f_{7}=7.129 \mathrm{~Hz}$. 
Stress ribbon bridges are very slender in nature and have a natural frequency very close to the pedestrian walking frequency of $2 \mathrm{~Hz}$ [1], [4], [5]. The codes of choice for structural engineers around the world for pedestrian excitation analysis are The British Standard BS 5400 Part 2 and Ontario Highway Bridge Design Code OHBDCONT 83 [3], [6]. For this article, I have used fib 32 guidelines and BS 5400 limiting criteria.

The fib 32 has a calculation method which determines the maximum vertical acceleration resulting from the passage of one pedestrian walking / running with a pace rate equal to the fundamental natural frequency of the bridge. Therefore, it is modelled as an equivalent single degree-of-freedom oscillator. The formula is given below,

$$
a=4 * \pi^{2} * f^{2} * y * \alpha * \emptyset
$$

Where, $a=$ Acceleration in $\mathrm{m} / \mathrm{s}^{2}$,

$f=$ Vertical natural frequency of the bridge in $\mathrm{Hz}$,

$\mathrm{y}=$ Static deflection at mid span in $\mathrm{m}$ for a force of $700 \mathrm{~N}$,

$\alpha=$ Fourier coefficient of the relevant harmonic of the walking or running rate,

$\varnothing=$ Dynamic amplification factor for one pedestrian moving across simple span (See Fig. 14).

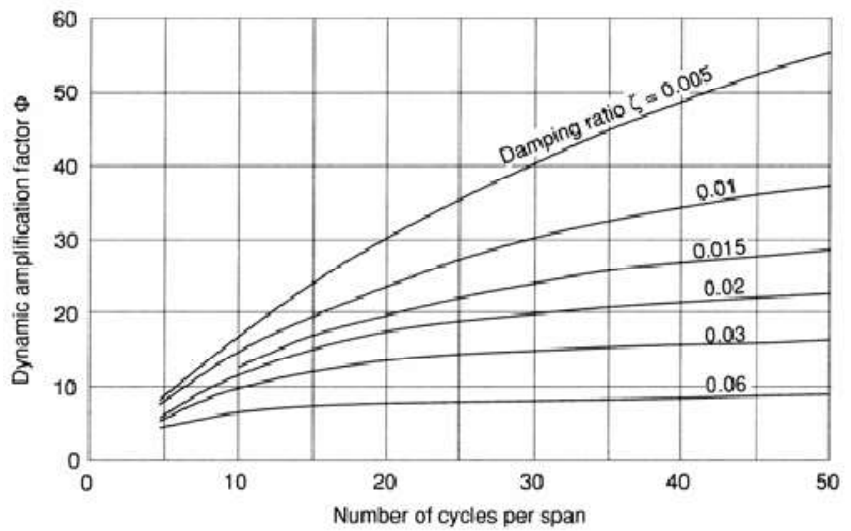

Fig. 14 Dynamic amplification factor.

For given conditions, the value of $\alpha$ would be 0.4 for a step frequency of $2 \mathrm{~Hz}$ for the first natural frequency and number of cycles per span for a $45 \mathrm{~m}$ span bridge is 60 [2]. BS 5400 Part 2 also considers the higher order harmonics of the structure and hence it has a limiting value of frequencies to be considered till $5 \mathrm{~Hz}$. However research has shown that higher order harmonics (frequency above $2.4 \mathrm{~Hz}$ ) will not produce important oscillations in a structure due to the lower force component of higher harmonics [2]. The permissible vertical acceleration is, $a_{V, \max }=0.5 * \sqrt{f}$. The results of pedestrian excitation is given in table 3 .

Table 3 Pedestrian Excitation Results

\begin{tabular}{|l|l|l|l|l|l|}
\hline $\begin{array}{l}\text { Frequency } \\
(\mathrm{Hz})\end{array}$ & $y(\mathrm{~m})$ & $\alpha$ & $\downarrow$ & $a\left(\mathrm{~m} / \mathrm{s}^{\mathrm{s}}\right)$ & $a_{V, \max }\left(\mathrm{m} / \mathrm{s}^{\mathrm{s}}\right)$ \\
\hline$f_{1}=1.379$ & 0.000508 & 0.4 & 25 & 0.381682 & 0.587154 \\
\hline$f_{2}=1.788$ & 0.000508 & 0.1 & 25 & 0.160416 & 0.668581 \\
\hline
\end{tabular}

The above table shows that the vertical accelerations of the bridge deck for the first two frequencies are well within the permissible limits and hence the pedestrians will not feel discomfort while walking on the bridge. Hence the bridge will be safe from pedestrian excitation at its critical frequencies.

\section{CONCLUSION}

The basic objective of this study is to elaborate on what a stress ribbon bridge is, its types and its advantages over conventional pedestrian bridges. This study elaborates on the various parameters essential before the actual design or analysis and the sources from which they are obtained. It also briefly explains the process of modelling, loading and analysis of a stress ribbon bridge in ANSYS. The critical conditions were identified and designed for manually. In this study a model of a stress ribbon bridge of 45 meter span is modelled and analyzed using ANSYS version 12 . the following conclusions can be made:

- Design of stress ribbon structures have confirmed that a slender concrete deck supported by an internal and/or external cables can be very efficient.

- Their designs have to be based on understanding of the cable tension, bending stiffness and on the understanding of the function of the prestressed concrete deck.

- The bending moment in a stress ribbon bridge is much lesser when compared to a beam because of its inverted arch shape.

- Temperature is a critical condition in a stress ribbon bridge due to its slender deck and flexible nature.

The abutment has to transfer high cable forces due to which it requires a very good stratum below it (preferably rock).

\section{REFERENCES}

[1] D. E. Newland, 2004. "Pedestrian excitation of bridges", Institution of Mechanical Engineers (IMechE), Volume 218, Part C, 477-492.

[2] Jiri Strasky, et al., 2005. "Guidelines for the design of footbridges", federation internationale du béton (fib), Bulletin 32.

[3] Jiri Strasky, 2006. "Stress Ribbon and Cable Supported Pedestrian Bridges", Academy of Sciences of the Czech Republic, Brno, Czech Republic.

[4] Jiri Strasky, 2008. "Stress Ribbon Pedestrian Bridges Supported or Suspended on Arches", Chinese-Croatian joint colloquium, Long Arch Bridges, Brijuni Islands, Croatia, 135-147.

[5] Jiri Strasky, 2010. "Stress Ribbon and Arch Pedestrian Bridges", 6th International Conference on Arch Bridges, Fuzhou, China, 38-45.

[6] Dr. Chung C. Fu, "Dynamic Response of Pedestrian Bridges", Research Professor, University of Maryland. 